\title{
Metamaterial Loaded Elliptical Ring Structured Mimo Antenna
}

\author{
M Purna Kishore, B T P Madhav, M Venkateswara Rao
}

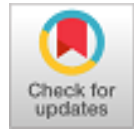

\begin{abstract}
The article proposes a MIMO isolation enhanced MIMO antenna for LTE bands, Bluetooth and Wi-Fi. The antenna is consisting of two radiating elements, where two are similar radiating elements separated by a distance. Another patch element is also added to create the peaks in the return loss. The antenna designed is working in the bands $1.29 \mathrm{GHz}-3.98 \mathrm{GHz}$, 7.12GHz-8.09GHz, 14.01GHz-15.82GHz and $17.64 \mathrm{GHz}-20 \mathrm{GHz}$. It has achieved good gain in the working bands of the antenna. The antenna is fabricated on $50 \times 60 \times 1.6 \mathrm{~mm} \wedge 3 \mathrm{FR}-4$ substrate with dielectric constant of 4.4. The antenna is analyzed and simulated using Ansys electromagnetic desktop 18. The other parameters such as gain, radiation patterns etc. are also discussed Index Terms: MIMO antenna, elliptical MIMO antenna.
\end{abstract}

\section{INTRODUCTION}

As the utilization of the cell phones increases, there is requirement of huge transmission capacity, which cause remarkable difficulties. Today the conveying recurrence is restricted in between $700 \mathrm{MHz}$ to $2.6 \mathrm{GHz}$. Some disjoint recurrence groups for range tasks contain diverse radio systems [1]. Best open door for circuit is existing in mm-wave for $60 \mathrm{GHz}$, as mm-waves are the high frequency waves which transfers huge data in less time and at higher data rates. As the advancements are being prodded by FCC by radio range groups, which may lead to rise in transfer speeds and progress. As these take place on one side, on other side there would be a quick progress in advancements of cell base stations, cellular equipment's mainly on the mobile phones and web. This leads to rise in higher rates of data transfer [2]. Now-a-days mobiles turned out to be extremely effective because it turned out to be a major part of the human life for communications and different needs. LTE and versatile Wi-Max, which utilizes OFDM and MIMO, which accomplish gigabit information rates up to few kilometers. The range $3-300 \mathrm{GHz}$, which is also called as mm-wave communication range [3]. Portability of phones has become increase in demand for mobiles which became an essential part of the human life, used in mobiles and satellites. Portable RF systems is the key part of the

Revised Manuscript Received on October 30, 2019.

* Correspondence Author

M Purna Kishore*, Dept. of ECE, Koneru Lakshmaiah Education Foundation, Vaddeswaram, Guntur District, India

B T P Madhav Dept. of ECE, Koneru Lakshmaiah Education Foundation, Vaddeswaram, Guntur District, India

M Venkateswara Rao, Dept. of ECE, Koneru Lakshmaiah Education Foundation, Vaddeswaram, Guntur District, India

(C) The Authors. Published by Blue Eyes Intelligence Engineering and Sciences Publication (BEIESP). This is an open access article under the CC BY-NC-ND license (http://creativecommons.org/licenses/by-nc-nd/4.0/) advancements in system. The RF system development also depends upon the urban spread of the microcell and figure out the transmitting power at transmitter end [4]. Mobiles are one of the fastest developing portable devices where its importance is reflected. The upcoming communication generations are intended to satisfy the prerequisites [5]. MIMO is one of the worthy innovations which can be used in upcoming generations of communication [6]. 5G mm-wave band is in between the range of $30-300 \mathrm{GHz}, 5 \mathrm{G}$ MIMO radio wire is produced by $3 \mathrm{D}$ printing by metal plating technique, where stereo lithography is used in the 3D printing innovation [7]. Introduction of MIMO has gradually expanded the channel limits, rise in information rates, gain and reliability [8]. There is a huge number of researchers are attracted to MIMO and mm-wave, but there are factors which are obstructing it gain its proficient stage like rain, distance between the transmitter and receiver [9]. MIMO share same plane, but the radiating elements are separated by a distance, due to which there might be a coupling effect between the radiating elements [10]. To reduce the effect of coupling few structures are being used in which one of the techniques is EBG, which reduces the wave spread, DGS is also a technique which can help through this effect of coupling [11]. The resonators in between the radiating elements can reduce the coupling effect, there are many types of resonators which can be introduced in between the elements by etching on the ground plane [12]. PIFA acts as a radiator inside the antenna which can reduce the effect of coupling but acquires huge area and if required PCB work is also included [13]. For improvements in this area there are techniques like LTCF and structures like PBG, DGS and SIW, DGS is mainly used in microwave circuits [14]. These DGS can really act as LPF which are in many forms and shapes like square and circle etc [15]. Due to MIMO, there are huge advantages in communication, like multiband, interoperability, bandwidth and gain etc [16]. PIN diodes are also used for switching the antenna's band where the antenna is interoperated between the bands achieved [17]. Due to multiple openings in antenna's radiating patch there arises a multi band characteristic antenna and wide bands [18]. UWB can also be achieved by using the MIMO structures, and can enhance the factors which can change the total performance of the antenna by using different types of structures and techniques [19-30]. In this article a metamaterial\loaded elliptical MIMO antenna is discussed. The designed antenna is used for low band frequencies such as LTE, Bluetooth and Wi-Fi applications. Along with that the isolation characteristics of the proposed antenna is also discussed. The MIMO antenna gain radiation patterns and current distributions and E-field is discussed in subsequent sections. 


\section{Metamaterial Loaded Elliptical Ring Structured Mimo Antenna}

\section{ANTENNA DESIGN}

The antenna's main concept is to dive into MIMO structures and adapt it to the lower frequency bands where we can achieve it for GSM, LTE, Bluetooth, and Wi-Fi bands. The antenna is designed in the way it reaches to the expectations of MIMO antenna structure and to reduce its coupling effect introducing the strip in between the two radiating elements present on the same sharing plane. A partial ground is introduced in the ground position. The antenna's radiating elements consist of a microstrip line feed and elliptical ring structures where the distance between the first two elliptical rings is half of the distance between the $2^{\text {nd }}$ and $3^{\text {rd }}$ elliptical ring, the rings create resonances.

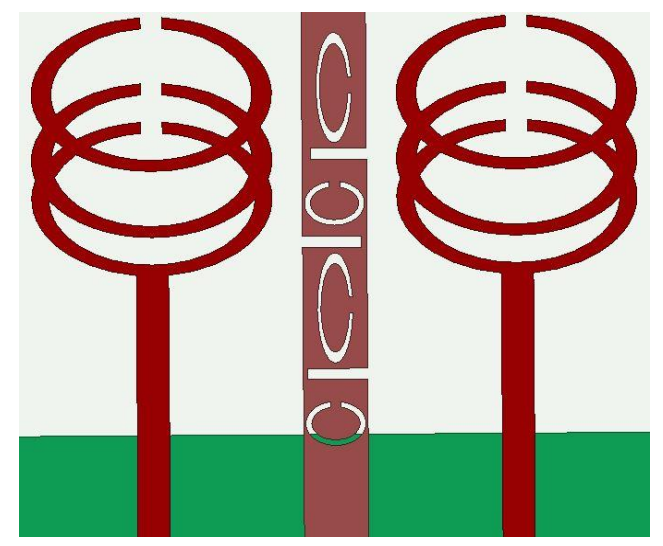

Fig 1- Proposed antenna.

The antenna with two radiating elements is introduced with a strip which reduces the effect of coupling between the radiating elements and creates resonances. At first a rectangular strip is taken into consideration and then elliptical rings and some small rectangular strip are removed from the patch strip introduced. Table 1 explains the dimensions of the proposed antenna.

TABLE 1: MEASUREMENTS (in mm)

\begin{tabular}{|l|l|l|l|l|l|l|l|l|l|l|l|l|l|}
\hline L & W & L1 & L2 & L3 & L4 & L5 & W3 & S1 & S2 & La & la & Ma & Ma \\
\hline 50 & 60 & 14 & 7 & 11 & 15 & 1 & 5 & 5 & 2.5 & 14 & 12 & 22 & 20 \\
\hline
\end{tabular}

\begin{tabular}{|l|l|l|l|l|l|l|l|l|l|l|l|l|l|}
\hline G1 & G2 & Lg & W2 & W1 & L6 & W5 & W6 & W7 & L7 & L8 & W4 & L9 & H \\
\hline 1.5 & 1 & 10 & 6 & 3 & 24.5 & 1 & 5.5 & 4.5 & 10 & 8 & 1 & 12.5 & 1.6 \\
\hline
\end{tabular}

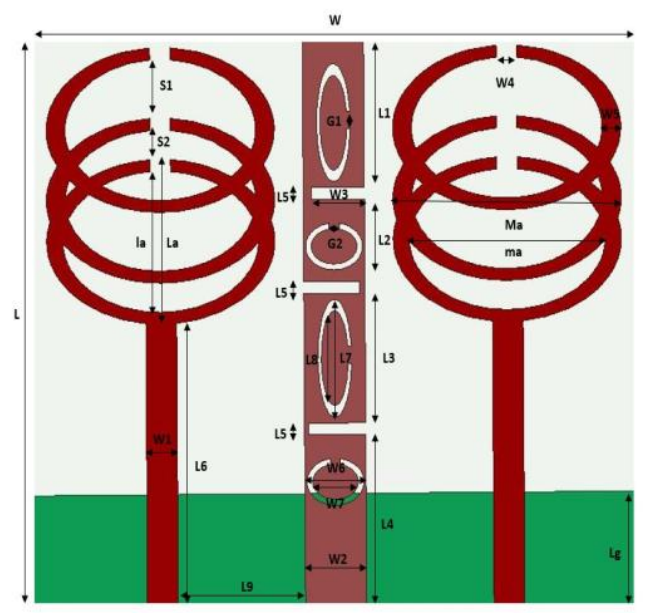

Fig- 2 Final antenna with measurements.

\section{RESULTS}

\subsection{Return Loss}

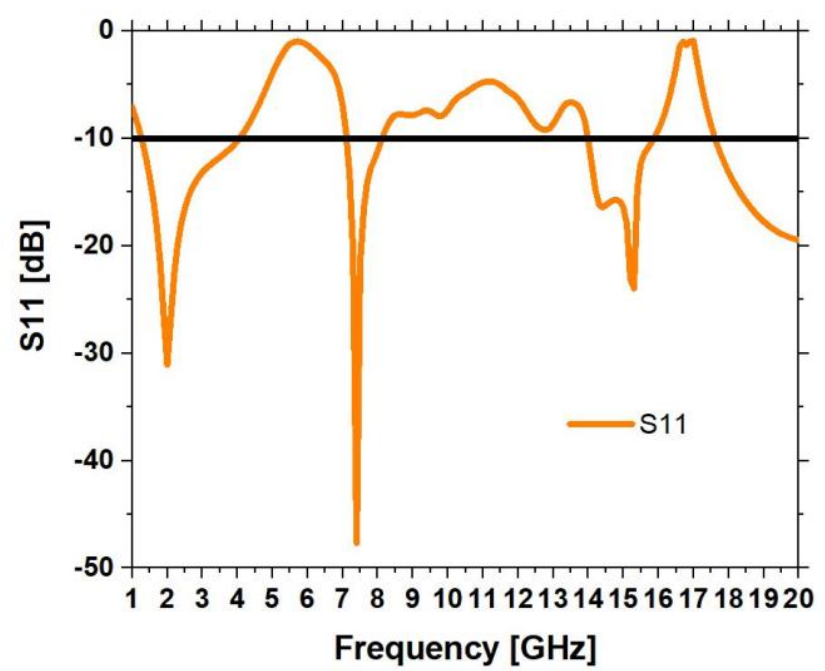

Fig - 3 Return loss of the proposed antenna.

The proposed MIMO antenna has achieved good return loss in the bands $1.29 \mathrm{GHz}-3.98 \mathrm{GHz}, \quad 7.12 \mathrm{GHz}-8.09 \mathrm{GHz}$, $14.01 \mathrm{GHz}-15.82 \mathrm{GHz}$ and $17.64 \mathrm{GHz}-20 \mathrm{GHz}$. It achieved a multi band, where the first band achieves many applications like GSM, LTE, Bluetooth and Wi-Fi.

\subsection{S-Parameters}

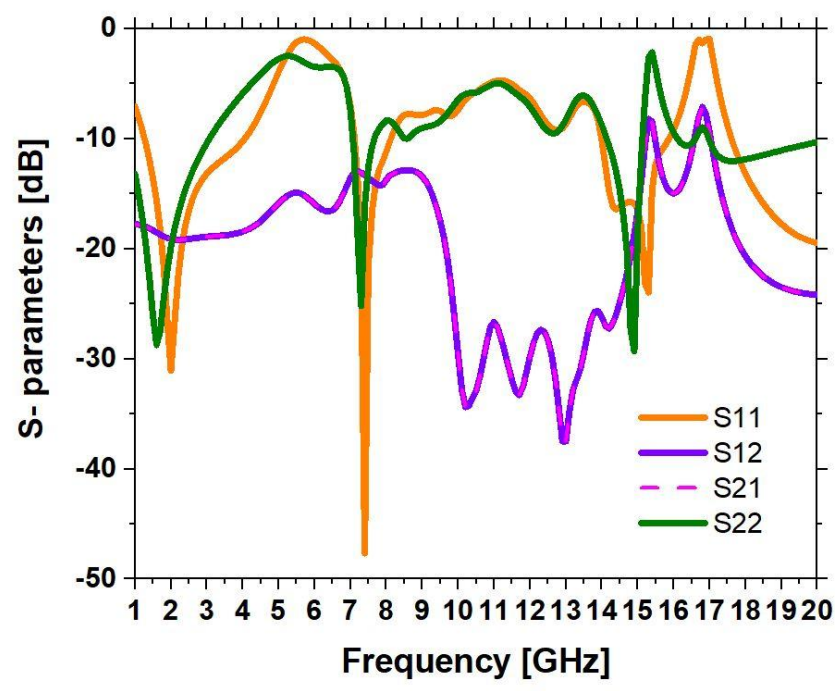

Fig - 4 S-parameters of the proposed antenna.

The S-parameters above in the diagram represent the simulated S-parameter of the proposed antenna where the S12 and S21 overlap over one another, the Return loss was good in some bands. 


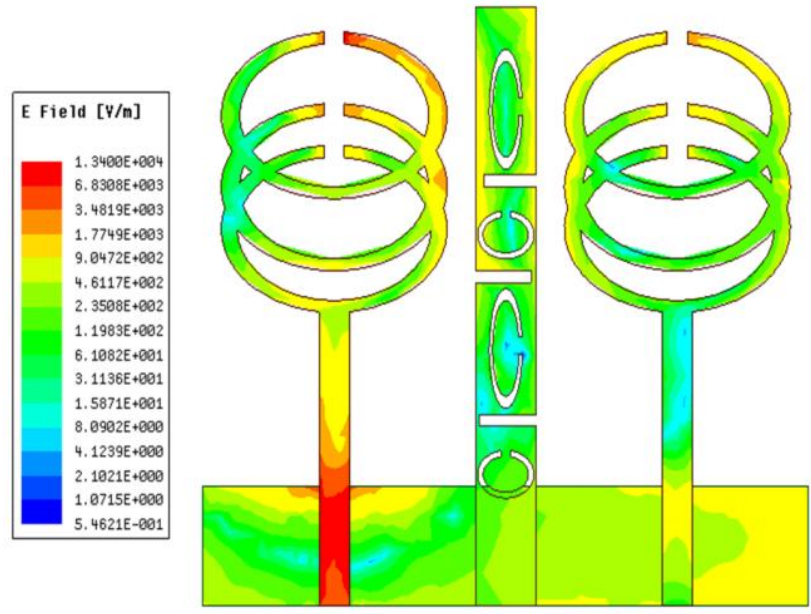

Fig - 5 E-field distribution pf proposed antenna at 2.1GHz

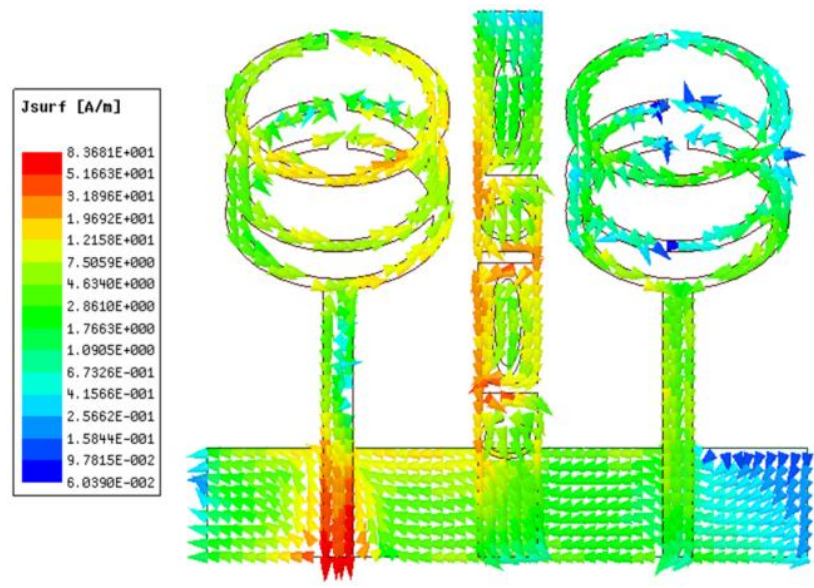

Fig 6 - Current distribution pf proposed antenna at 2.1GHz

\subsection{GAIN}

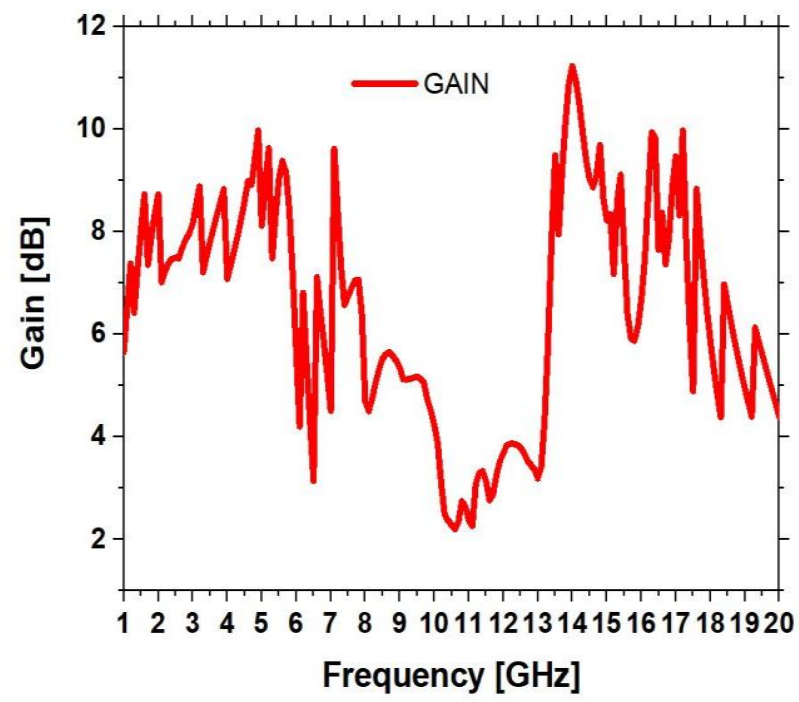

Fig -7 Gain of the proposed antenna.

The proposed antenna has achieved positive gain all over the band. The antenna has achieved higher gain at higher frequencies. The gain at the working bands were good and promising. The gain dropped $9 \mathrm{GHz}$ and regained itself near $15 \mathrm{GHz}$.

\subsection{Radiation patterns}

The antenna proposed have achieved peaks at $2 \mathrm{GHz}$ and $7.4 \mathrm{GHz}$ where the antenna radiation patterns were taken into consideration and the results of the radiation patterns in $\mathrm{XY}$, YZ, ZX planes achieved are good. The results are shown below in the figure8 and figure 9.

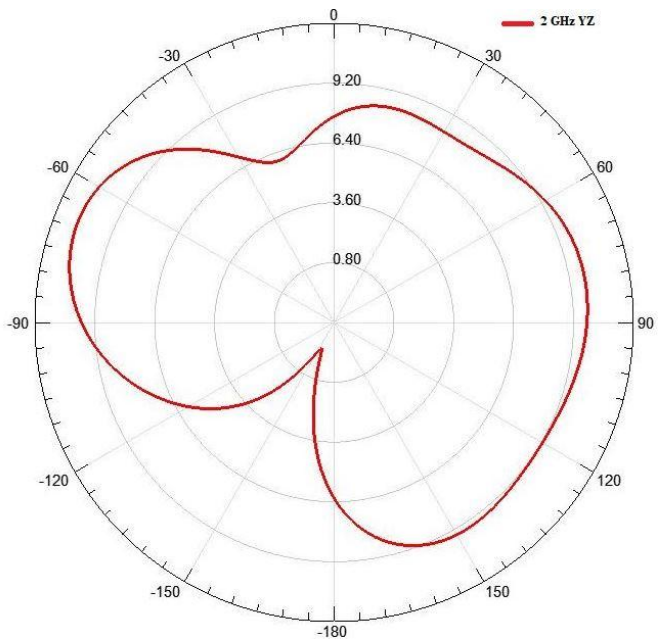

(a)

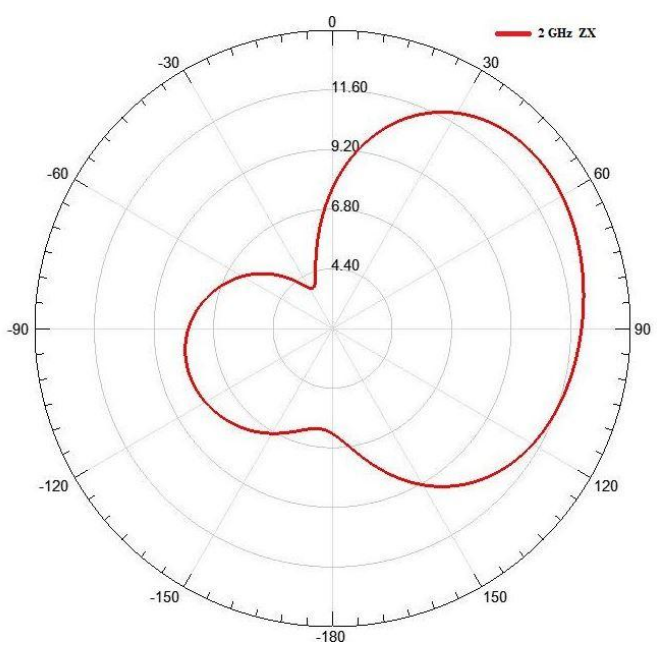

(b)

Fig - 8 Radiation patterns of the proposed antenna at

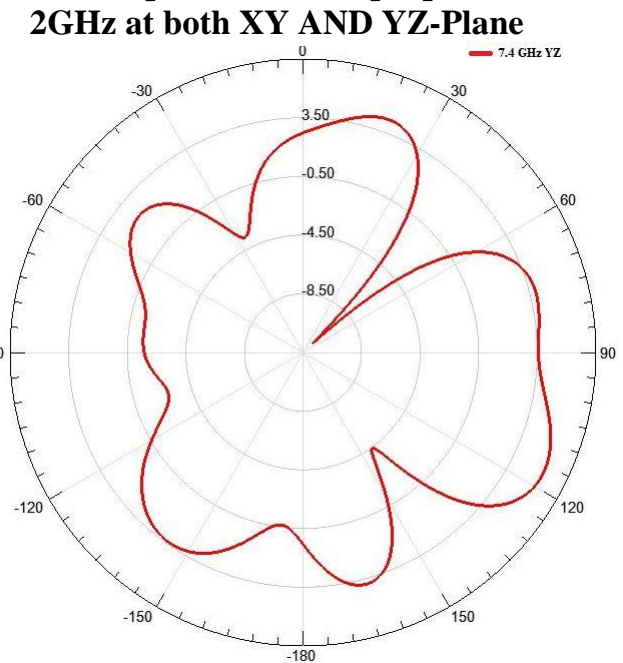

(a) 


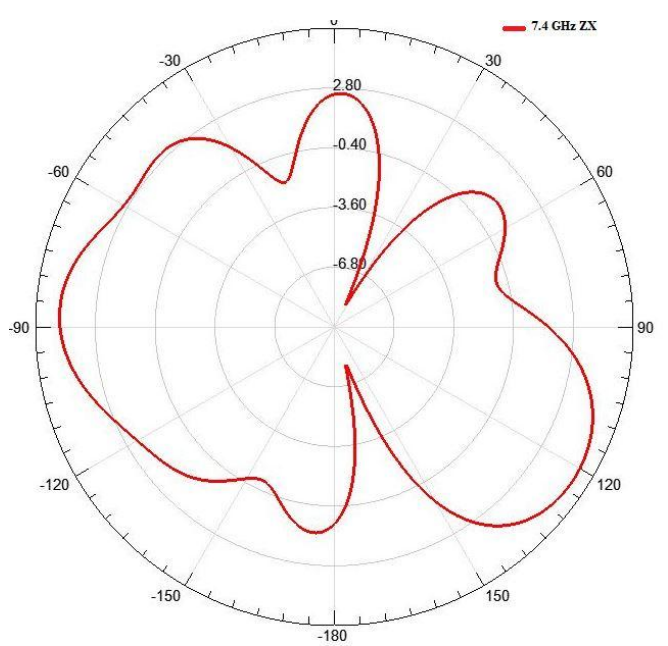

(b)

Fig - 9 Radiation patterns of the proposed antenna at 7.4GHz at XY And YZ-Plane

\section{CONCLUSION}

An elliptical ring structured MIMO antenna is proposed for GSM and LTE bands and also works in the Bluetooth and Wi-Fi bands. which achieved a $2.69 \mathrm{GHz}$ band which contains the main applications of communication from 1.12GHz-3.98GHz. It achieved positive gain all through the band. To enhance the characteristics of the antenna, the patch strip was introduced to reduce coupling effect and partial ground to increase the bandwidth and gain. The elliptical ring patches create resonances in the frequency bands. The antenna proposed works in the required bands of mobile communications. The antenna design and simulation are totally done in AEDT software.

\section{ACKNOWLEDGEMENTS}

We would like to thank Dept of ECE, KLEF for their continuous support and DST for their technical support through ECR/2016/000569 and EEQ/2016/000604 grants.

\section{REFERENCES}

1. Venkateswara Rao, Manikonda, et al. "CSRR-loaded T-shaped MIMO antenna for 5G cellular networks and vehicular communications." International Journal of RF and Microwave Computer-Aided Engineering: e21799.

2. Boddapati, Madhav, and Purna Kishore. "Bandwidth Enhancement of CPW-Fed Elliptical Curved Antenna with Square SRR." International Journal of Intelligent Engineering and Systems 11.2 (2018): 68-75.

3. Rao MV, Madhav BT, Anilkumar T, Nadh BP. Metamaterial inspired quad band circularly polarized antenna for WLAN/ISM/Bluetooth/WiMAX and satellite communication applications. AEU-International Journal of Electronics and Communications. 2018 Dec 1;97:229-41.

4. Ojaroudiparchin $\mathrm{N}$, Shen $\mathrm{M}$, Pedersen GF. Investigation on the performance of low-profile insensitive antenna with improved radiation characteristics for the future 5G applications. Microwave and Optical Technology Letters. 2016 Sep;58(9):2148-51.

5. Nor NM, Jamaluddin MH, Kamarudin MR, Khalily M. Rectangular dielectric resonator antenna array for $28 \mathrm{GHz}$ applications. Progress In Electromagnetics Research. 2016;63:53-61.

6. Ali MM, Haraz O, Alshebeili S. Design of a dual-band printed slot antenna with utilizing a band rejection element for the 5G wireless applications. In2016 IEEE International Symposium on Antennas and Propagation (APSURSI) 2016 Jun 26 (pp. 1865-1866). IEEE.

7. Madhav BT, Devi GJ, Lakshman P, Anilkumar T. A CPW-fed Sigma-shaped MIMO Antenna for Ka Band and 5G Communication
Applications. Journal of Telecommunications and Information Technology. 2018 Oct 1(4):97.

8. Babu MA, Madhav BT, Vaishnavi DN, Radhakrishna P, Bharath N, Madhuri K, Prasad KB, Harish K. Flared V-shape slotted monopole multiband antenna with metamaterial loading. International Journal of Communications Antenna Propagation. 2015;5(2):93-7.

9. Bhavani KV, Khan H, Madhav BT. Multiband slotted aperture antenna with defected ground structure for $\mathrm{C}$ and $\mathrm{X}$-band communication applications. Journal of Theoretical and Applied Information Technology. 2015 Dec 1;82(3):454.

10. Lakshmi ML, Khan H, Madhav BT. Novel Sequential Rotated 2x2 Array Notched Circular Patch Antenna. Journal of Engineering Science and Technology Review. 2015 Oct 1;8(4):73-7.

11. Lakshmikanth P, Takeshore K, Madhav BT. Printed Log Periodic dipole antenna with Notched filter at $2.45 \mathrm{GHz}$ Frequency for wireless communication applications. Journal of Engineering and Applied Sciences, ISSN. 1816:40-4.

12. Lakshmi MLSNS, et al. (2015). Novel sequential rotated $2 \times 2$ array notched circular patch antenna. J Eng Sci Technol Rev, 8(4), pp73-77.

13. Khan H, et al. (2013). Substrate permittivity effects on the performance of slotted aperture stacked patch antenna. Int J Appl Eng Res 8(8), pp.909-916

14. Kotamraju SK. (2016). Circularly polarized slotted aperture antenna with coplanar waveguide fed for broadband applications. J Eng Sci Tech, 11(2), pp.267-277.

15. Bhavani KVL. (2015). Multiband slotted aperture antenna with defected ground structure for $\mathrm{C}$ and $\mathrm{X}$-band communication applications. J Theor Appl Inf Tech, 82(3), pp.454-461.

16. Prasad PVD. (2011). Microstrip $2 \times 2$ square patch array antenna on K15 liquid crystal substrate. Int J Appl Eng Res, 6(9), pp.1099-104. that will be maximum 200-400 words.

17. M. Venkateswara Rao, and T. Anilkumar. "Conformal Band Notched Circular Monopole Antenna Loaded with Split Ring Resonator." Wireless Personal Communications 103.3 (2018): 1965-1976

18. Sujatha, M., et al. "Tristrip Monopole Antenna with Split Ring Resonators for ISM Band Biomedical Applications." Indian Journal of Public Health Research \& Development 9.6 (2018).

19. Prakash, B. L., et al. "Metamaterial Inspired Tri-Band Antenna with SRR and Shorting Stub." ARPN Journal of Engineering and Applied Sciences, ISSN 6608 (1819): 6197-6205.

20. Rao, M. V., et.al. (2017). Quad Band Filtenna using Split Ring Resonators to Notch Unwanted Frequencies in Medical Application Bands. Journal of Theoretical and Applied Information Technology, 95(9) 